\title{
Diagnostic value of glypican-3 in alpha fetoprotein negative hepatocellular carcinoma patients
}

\author{
Li B ${ }^{1}$, Liu $\mathrm{H}^{2}$, Shang $\mathrm{HW}^{3}$, Li P ${ }^{1}$ Li N ${ }^{1}$, *Ding $\mathrm{HG}^{1}$
}

1. Department of Hepatology and Gastroenterology, Beijing You'An Hospital affiliated to Capital Medical University, 100069, China.

2. Department of Pathology, Beijing You'An Hospital affiliated to Capital Medical University, 100069, China. 3. School of Basic Medical Sciences, Capital Medical University, 100069, China.

\begin{abstract}
Background: The prognosis of patients with hepatocellular carcinoma(HCC) is generally very poor with a 5 -year survival rate of less than $15 \%$ since most of them are diagnosed clinically at their late stage. However,the differential diagnosis between alpha fetoprotein(AFP) negative HCC and cirrhotic nodules is still difficult.

Objectives: To evaluate the diagnostic value of glypican-3(GPC3) in patients with AFP negative hepatitis B related HCC. Methods The liver tissue GPC3 (GPC3L) expression was tested from 426 for surgery and 179 of needle biopsies of hepatitis B related HCC patients using immunohistochemistry staining. Serum GPC3 (GPC3S) and AFP were also measured. Results Among surgical HCC samples, $80.0 \%$ of GPC3L expression was positive, however, in paracarcinomatous and cirrhotic nodules were negative. In needle biopsy tissues, GPC3L positively expression was in $74.9 \%$. The sensitivity of $\mathrm{AFP}>400 \mu \mathrm{g} / \mathrm{L}$ was $25.4 \%$. The GPC $3 \mathrm{~S}>3.5 \mu \mathrm{g} / \mathrm{L}$ was determined as a positive. The area of ROC curve of GPC3S was $0.68(95 \%$ CI 0.56-0.79,P $<0.05)$ in all HCC patients, 0.81 (95\% CI $0.62-0.98, \mathrm{P}<0.05)$ in AFP greater or equal to $400 \mu \mathrm{g} / \mathrm{L}$ and $0.64(95 \% \mathrm{CI} 0.51-0.77, \mathrm{P}=0.051)$ in AFP negative patients. The GPC3S was positive in $48.8 \%$ of patients with AFP negative. No difference was observed between GPC3L/GPC3S and serum AFP.

Conclusions GPC3 may be helpful in improving diagnosis of HCC and in differentiating diagnosis between AFP negative HCC and cirrhotic nodules.
\end{abstract}

Key words: Hepatocellular carcinoma; Glypican-3; Differential diagnosis, Alpha fetoprotein, Hepatitis B African Health Sciences 2013; 13(3): 703 - 709 http://dx.doi.org/10.4314/ahs.v13i3.26

\section{Introduction}

The hepatocellular carcinoma HCC is one of the most common malignant tumor in the world, especially in China, because the main etiological factor of HCC in China is HBV infection ${ }^{1}$. The prognosis of patients with HCC is generally very poor with a 5 -year survival rate of less than 15\% since most of them are diagnosed clinically at their late stage ${ }^{2}$. Therefore, early detection and diagnosis is still the key way to improve the prognosis of $\mathrm{HCC}^{3}$. Screening for HCC is considered to be cost-effective in patients with cirrhosis since the population has an expected annual incidence of HCC exceeding 5\% per year ${ }^{4}$. However, most of cases of liver mass/

*Corresponding author:
Dr. Huiguo Ding
Department of Gastroenterology and Hepatology
Beijing You'an Hospital affiliated to Capital Medical
University
Beijing 100069
China
Telephone: +86-10-83997155
E-mail: dinghuiguo@medmail.com.cn

African Health Sciences Vol 13 Issue 3 September 2013 nodular lesions are benign, such as cirrhotic regenerative nodules, adenoma, and focal nodular hyperplasia, but they may mimic malignant liver lesions both clinic and radiology $y^{5}$. The hepatocellular carcinoma also show a variety of histological patterns. The pathologic diagnosis of HCC using routine histological stains is usually difficult, especially for well differentiated tumors or small biopsy specimens. Immunohistochemistry has been applied extensively to hepatic neoplasms for the differential diagnosis ${ }^{6,7}$. Monoclonal antibodies including HepPar-1, cytokeratin 7(CK7), cytokeratin 19(CK19), cytokeratin 20(CK20), thyroid transcription factor-1 (TTF-1, carcinoembryonic antigen (CEA), CD34, alpha fetoprotein (AFP) were usually used to differentiate HCC, cholangiocarcinoma and other metastatic tumors. However, they are hardly useful to identify hepatic benign or malignant nodules ${ }^{8,9,10}$. Therefore, the differential diagnosis between hepatitis B related HCC and benign cirrhotic nodules is still a problem. Glypican-3 (GPC3) is a member of the heparan sulfate proteoglycan family, which is linked to the 
cell surface through a glycosylphosphatidylinositol anchor ${ }^{11}$. Glypicans play an important role in cell growth, differentiation, and migration ${ }^{12,13,14}$. It has been reported many times that GPC3 messenger RNA (mRNA) and protein level are increased in a large proportion of $\mathrm{HCC}^{15,16,17,18,19}$. Capurro et al. found overexpression of GPC3 protein in $72 \%$ of HCC, but no overexpression was detected in focal nodular hyperplasia and cirrhotic liver ${ }^{18}$. GPC3, therefore, seems useful to differentiate preneoplastic from well-differentiated neoplastic hepatocellular disorders or benign cirrhotic nodules and HCCs. However, the relationship between hepatic GPC3 expression and serum GPC3 and AFP is unclear. The differential diagnostic value of GPC3 between AFP negative HCC and cirrhotic nodules is still not reported. Therefore, the aim of this study was to assess GPC3 for the differential diagnostic value in patients with AFP negative hepatitis B related HCC.

\section{Methods}

\section{Liver tissue and Serum samples}

Total 605 patients with hepatitis B related HCC proved by hepatic histology at Beijing YouAn Hospital, Capital Medical University were recruited from January 2007 to May of 2012. The ages of patients with HCC ranged from 32 to 84 years (mean, 49.8 years), and the male/female ratio was 3.3:1. All of these patients were $\mathrm{HBsAg}$ positive. The liver tissue samples were obtained from 426 HCC patients by surgery resection liver tissue including carcinoma and paracarcinomatous (far away edging of carcinoma more than $2 \mathrm{~cm}$ ), and 179 by needle biopsies from liver mass/nodular lesions. All the specimens were fixed in 4\% neutral buffered formalin and embedded in paraffin. Four-ìm thick tissue slides were made from whole tissue blocks. The slides were reviewed to confirm the HCC diagnosis as the guidelines of WHO's criteria ${ }^{20}$. All tissue samples were reviewed by 2 experienced pathologists. The serum samples from these patients, including age and gender matched 25 health volunteers, were kept in the Medical Bioinformation Research Center Serum Bank at $80^{\circ} \mathrm{Cfor}$ measurement of serum GPC3 and AFP. The health volunteers were defined as liver function test and B-ultrasonography normal and $\mathrm{HBsAg}$ negative. The study protocol was approved by the Ethical Committee of Beijing YouAn Hospital, Capital Medical University. Investigators explained in detail to all the patients and/or their relatives. Consent forms were obtained from all participants before recruitment.

\section{Immunohistochemistry (IHC) staining}

The expression of liver tissue GPC3 (GPC3L) was measured using IHC staining. Monoclonal anti-GPC3 antibody (clone number: sc-65443 1G12, Santa Cruz Inc, USA) were used in the IHC staining. Mouse negative control was also used as control. In briefly, tissue sections were deparaffinized and rehydrated. Endogenous peroxidase activity was blocked by using 3\% hydrogen peroxide for 10 minutes. Following heat-induced in $0.1 \mathrm{~mol} / \mathrm{L}$ of citrate buffer at $\mathrm{pH} 6.0$ using microwaves for 8 minutes, the slides were incubated in pepsin for 7 minutes and subsequently incubated with 1:50 diluted primary antibodies overnight at 4 !. The secondary antibody used was horse-radish peroxidase (HRP)-labeled antibody (Zhongshan Goldenbridge Company, Beijing, China) for 30 minutes at room temperature. The reaction product was shown using 3, 39diaminobenzidine tetrahydrochloride and the sections were counterstained with hematoxylin. The results were evaluated by board certificated pathologists. The area of GPC3 staining $>5 \%$ was positively considered.

\section{Serum AFP and GPC3}

Serum AFP was tested by electrochemiluminescence (reagents from Abbott Ltd, USA). The serum $\mathrm{AFP}<400 \mu \mathrm{g} / \mathrm{L}$ was regarded as negative according to Chinese and Asia guideline ${ }^{21,22}$. Serum GPC3(GPC3S) was determined by enzyme linked immunosorbent assay (ELISA) (GPC3 ELISA Kit, Catalog No. CSB-E11333h (96T), Cusabio biotech co. Ltd, Shanghai, China) following the protocol provided by manufacturer. The cutoff value of GPC3S was determined by receiver-operator characteristic curve (ROC) curve, which is 2SD above the average of the healthy individuals. The optical density was measured using spectrophotometer (Bio-Rad xMark, USA).

\section{Statistical analysis}

All analyses performed using the SPSS statistical software pack for windows (version 11.5). The differences of the mean of GPC3S between the subgroups were determined by the unpaired sample $\mathrm{t}$ test. The ROC curve of GPC3S was performed to determine the diagnostic accuracy and two by two tables for sensitivity and specificity. The categorical variable was compared using the $X^{2}$ test with Pearson correction. The difference was considered as significant when $P<0.05$. 


\section{Results}

Expression of GPC3 in HCC tissues

By using IHC staining, GPC3L was easily detected to express in HCC specific cells, and no expression in paracarcinomatous and cirrhotic nodules tissue (figure 1A-C). Positive cell staining was restricted to the area of HCC differentiation. The non-HCC tissues, including cirrhotic nodules or paracarcinomatous, were consistently negative. It was found GPC3L was positive in 80.0\% $(341 / 426)$ of the HCC excised tissue samples. Of those patients, GPC3L was positively expressed in $81.2 \%$ (147/ 181) well-differentiated, $81.1 \%(86 / 106)$ moderately differentiated and $77.7 \%(108 / 139)$ poordifferentiated HCCs. There was no significant difference of GPC3L among HCC differentiation degree ( $\mathrm{P}>0.05)$. GPC3L was positive in $74.9 \%$ $(134 / 179)$ of needle biopsy tissues from HCC patients. There was no difference of GPC3L expression between surgery tissue and needle biopsy samples.

No difference between GPC3L and serum AFP The sensitivity of serum AFP greater or equal to $400 \mu \mathrm{g} / \mathrm{L}$ for diagnosis HCC was $25.4 \%$ (table 1). The GPC3L expression was detected in $77.4 \%$ (328/
424) of patients with serum AFP negative and in $81.2 \%(147 / 181)$ of patients with AFP greater or equal to $400 \mu \mathrm{g} / \mathrm{L}$ in figure $2 \mathrm{~A}$. No difference was observed between GPC3L and serum AFP.

The mean of GPC3S in patients with AFP $<400 \mu \mathrm{g} /$ $\mathrm{L}(12.63 \pm 2.93 \mu \mathrm{g} / \mathrm{L})$ or $\mathrm{AFP}$ greater or equal to $400 \mu \mathrm{g} / \mathrm{L}(20.20 \pm 5.41 \mu \mathrm{g} / \mathrm{L})$ was significantly higher than in controls $(1.92 \pm 0.95 \mu \mathrm{g} / \mathrm{L}, \mathrm{P}<0.01)$ (figure $2 \mathrm{~B}$ ). According to ROC curve $\left(\mathrm{r}^{2}=0.96, \mathrm{~F}=162.1\right.$, $\mathrm{P}<0.01)$, the cutoff value was $3.5 \mu \mathrm{g} / \mathrm{L}$ of GPC3S to determine HCC as a positive. The sensitivity and specificity in all, AFP greater or equal to $400 \mu \mathrm{g} / \mathrm{L}$ and AFP negative HCC patients were 54.6\%, 75\%, $54.6 \%$ and $80 \%, 80 \%, 76 \%$, respectively. Their positive predictive value and negative predictive value were $83.3 \%, 60 \%, 77.8 \%$ and $43.2 \%, 86.4 \%, 46.3 \%$, respectively. The area under a ROC curve of GPC $3 \mathrm{~S}$ in all, AFP greater or equal to $400 \mu \mathrm{g} / \mathrm{L}$ and $\mathrm{AFP}$ negative HCC patients was $0.68(95 \%$ CI $0.56-0.79$, $\mathrm{P}<0.05), 0.81$ (95\% CI, $0.62-0.98, \mathrm{P}<0.05)$ and 0.64 (95\% CI, 0.51- 0.77, $\mathrm{P}=0.051$ ) (figure 3). In this study, the GPC3S was positive in $48.8 \%$ of patients with serum AFP negative. The no difference between GPC3S and GPC3L expression was also observed.

Table 1: The sensitivity and specificity of different AFP cut-off value for diagnosis of HCC

\begin{tabular}{lllllc}
\hline Cutoff & \multicolumn{5}{c}{ Evaluation indicators $(\mu \mathrm{g} / \mathrm{L})$} \\
\hline & SEN & SPE & +LR & -LR & OR \\
20 & 0.55 & 0.73 & 2.01 & 0.62 & 3.22 \\
200 & 0.32 & 0.96 & 8.11 & 0.70 & 11.52 \\
400 & 0.25 & 0.98 & 10.58 & 0.76 & 13.85 \\
\hline
\end{tabular}

SEN, Sensitivity; SPE, specificity; +LR, Positive likelihood ratio; -LR, Negative likelihood ratio; OR, Diagnostic odds ratio.
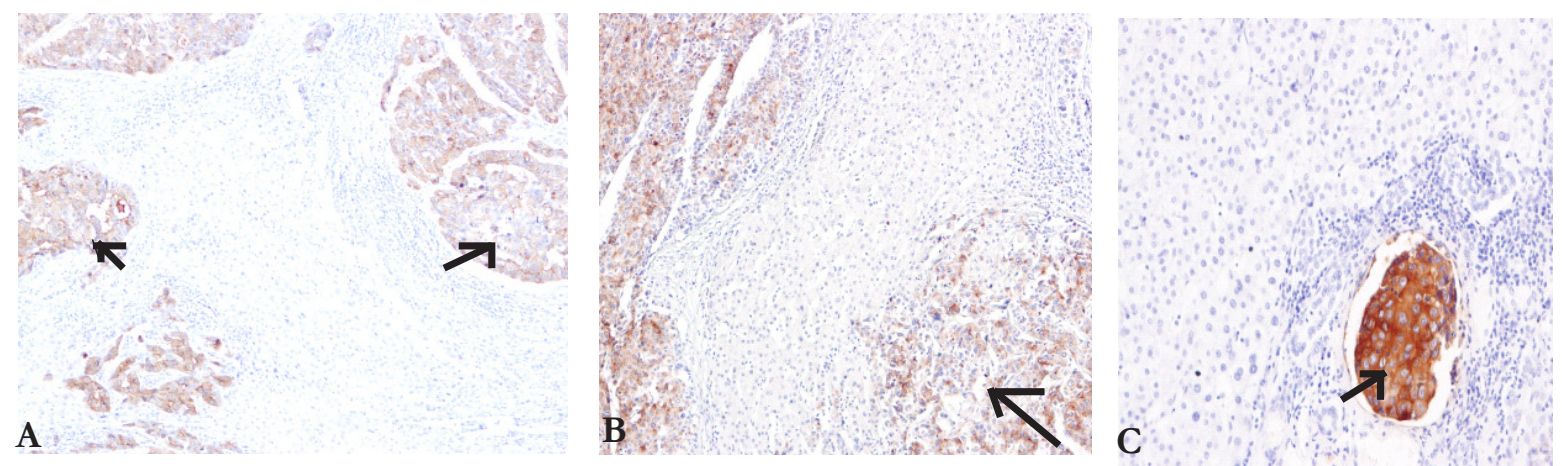

Figure 1: IHC staining of GPC3 in HCC liver samples A-C (10x). The cells stained with brown particles were considered as positive (arrow).

A: The area of cirrhosis liver around the HCC has no GPC3 expression.

B: There was no labeling in area with non-cirrhosis liver around the HCC.

C: The area of portal venous tumor thrombus showed strong GPC3 expression(arrow). 

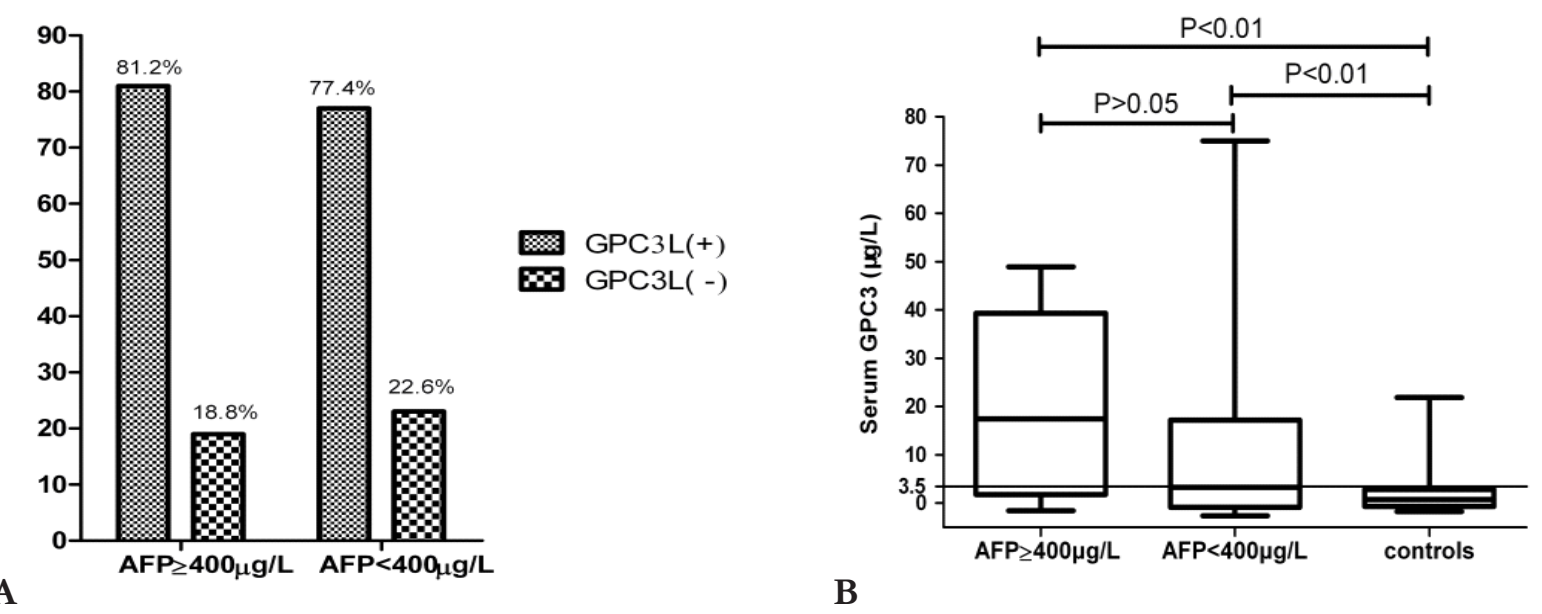

Figure 2 A-B: The relationship between GPC3L/GPC3S with serum AFP

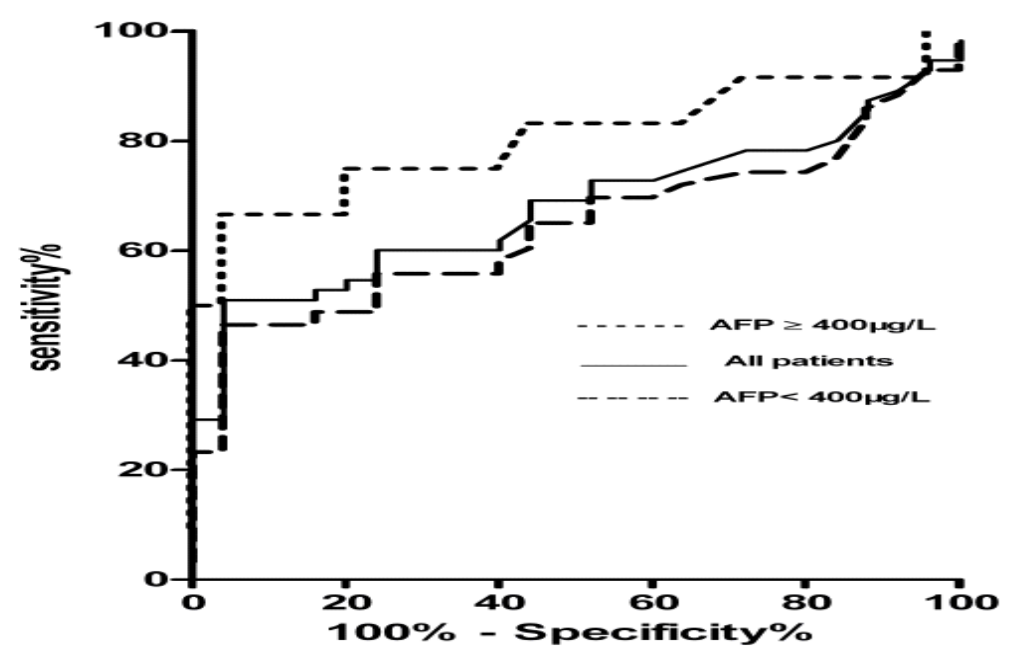

Figure 3: The diagnostic accuracy of GPC3S was performed by ROC curves.

The GPC3S was over $3.5 \mu \mathrm{g} / \mathrm{L}$ in $48.8 \%$ of patients with AFP $<400 \mu \mathrm{g} / \mathrm{L}$. The sensitivity and specificity in all, AFP greater or equal to $400 \mu \mathrm{g} / \mathrm{L}$ and AFP negative HCC patients were $54.6 \%, 75 \%, 54.6 \%$ and $80 \%, 80 \%$, $76 \%$, respectively. The positive predictive value and negative predictive value were $83.3 \%, 60 \%, 77.8 \%$ and $43.2 \%, 86.4 \%, 46.3 \%$, respectively.

The morbidity of HCC is raised in liver cirrhosis or chronic hepatitis B patients in China ${ }^{23-24}$. The pathological diagnosis of HCC using routine histological stains is usually difficult because of variety of histopathological patterns, especially for well differentiated tumors or small biopsy specimens. Immunohistochemistry has been applied extensively to hepatic neoplasms for the differential diagnosis and a number of immunomarkers have been widely utilized to facilitate the distinction HCCs from benign lesions. However, the currently available immunomarkers have significantly limited ${ }^{9-10}$. For example, monoclonal HepPar-1 antigen does not discriminate benign from malignant hepatocytes and tends to be nonimmunoreactive in poorly differentiated HCCs. AFP, which expressed well in fetal livers, shows low sensitivity in HCC and is seldom used in our routine work for HCC diagnosis. CK19 or CK7 is useful in distinguishing HCCs from cholangiocarcinomas, but there is no use to distinct hepatic cellular benign and malignant lesions either. In a word, all of these antibodies for IHC can't discriminate between benign and malignant hepatocytes.

In this study, we found GPC3L was positive in $80.0 \%$ of the HCC patients for surgery excised tissue and $74.9 \%$ of needle biopsy samples. However, GPC3L negative expression in paracarcinomatous 
and cirrhotic nodules was found. Some recent studies had reached the same conclusion that none of cirrhotic livers and non-neoplastic liver tissues exhibited positive GPC3 immunostaining using different methods ${ }^{25,26,27}$.

In recently study on prospective validation of an immunohistochemical panel -GPC3, heat shock protein 70(HSP70) and glutamine synthetase (GS) in liver biopsies for diagnosis of very early hepatocellular carcinoma has been done by Dr. Tremosini $\mathrm{S}^{28}$. It was found that the sensitivity and specificity for HCC diagnosis were: GPC3 57.5\% and $95 \%$, HSP $7057.5 \%$ and $85 \%$, GS $50 \%$ and $90 \%$, respectively. However, the sensitivity and specificity of the different combinations were significantly increased. These data support the guideline of AASLD on immunohistochemical staining of GPC3 for the diagnosis of early HCC $^{29}$. Therefore, it is strongly supported that GPC3L may be usefull to differenate between HCC and cirrhotic nodules. The results are different from some previous reports which reported 3\%-19\% expression in nonneoplastic and preneoplastic disorders ${ }^{30}$.

The serum AFP is the widely used tumor marker in the diagnosis of HCC for 40 years. In recently, the diagnostic value of serum AFP is questioned because of very low sensitivity ${ }^{29,31}$. In this study, the sensitivity of serum AFP greater or equal to $400 \mu \mathrm{g} / \mathrm{L}$ for diagnosis HCC was $25.4 \%$. However, the data of serum GPC3 for diagnosis HCC are limitation. Ozkan H,et al. had recently reported that the sensitivity, specificity, and positive and negative predictive values of serum GPC 3 was $61.33 \%, 41.82 \%, 58.97 \%$, and $44.43 \%$, respectively. It is suggested that serum GPC3 is not a useful diagnostic and prognostic marker for HCC ${ }^{32}$. However, in this study, it is firstly reported that the GPC3L expression was detected in $77.4 \%$ of patients with serum AFP negative and in $81.2 \%$ of patients with AFP greater or equal to $400 \mu \mathrm{g} / \mathrm{L}$. It is interestingly found that there is no difference between GPC3L and serum AFP. GPC3L was highly expressed in patients with serum AFP negative $($ AFP $<400 \mu \mathrm{g} / \mathrm{L}) \mathrm{HCC}$. The area under a ROC curve of GPC3S was 0.68 in all HCC patients, 0.81 in serum AFP greater or equal to $400 \mu \mathrm{g} / \mathrm{L}$ and 0.64 in patients with serum AFP negative. Our study was also found GPC3S was significantly positive in $54.6 \%$ of patients with HCC, especially in serum AFP negative HCC. Therefore, these data is strongly suggested that combinations of serum AFP and GPC3S may increase diagnostic sensitivity, especially for early diagnosis of HCC.

\section{Conclusion}

We confirmed the high and specificity expression of GPC3L in HCC tissue as a diagnostic marker. GPC3 may be very helpful in improving diagnosis of HCC and in differentiating diagnosis between AFP negative HCC and cirrhotic nodules. The combination test of serum AFP and GPC3S may increase the early diagnosis of HCC. It would be mentioned for clinicians in routine clinical practice.

\section{Acknowledgements}

This study was funded by Major Projects on Infectious Disease (2012 ZX10002008-005) and Beijing Science and Technology Commission research projects (No. H010210110129, Z111107058811067), and High-Level Talent Academic Leader Training Program (2011-2-19).

\section{References}

1. Poon D, Anderson BO, Chen LT, Tanaka K, Lau WY, Van Cutsem E, et al. Management of hepatocellular carcinoma in Asia: consensus statement from the Asian Oncology Summit 2009. Lancet Oncol 2009;10: 1111-8.

2. Kawano Y, Sasaki A, Kai S, Endo Y, Iwaki K, Uchida $\mathrm{H}$, et al. Short- and long-term outcomes after hepatic resection for hepatocellular carcinoma with concomitant esophageal varices in patients with cirrhosis. Ann Surg Oncol 2008;15: 1670-6.

3. Befeler AS, Di Bisceglie AM. Hepatocellular carcinoma: diagnosis and treatment. Gastroenterology 2002;122. 1609-1619 .

4. Thompson Coon J, Rogers G, Hewson P, Wright D, Anderson R, Jackson S, et al. Surveillance of cirrhosis for hepatocellular carcinoma: a costutility analysis. Br J Cancer 2008;98: 1166-75.

5. Libbrecht L, Severi T, Cassiman D, Vander Borght S, Pirenne J, Nevens F, et al. Glypican-3 expression distinguishes small hepatocellular carcinomas from cirrhosis, dysplastic nodules, and focal nodular hyperplasia-like nodules. $A m$ J Surg Pathol 2006;30: 1405-11.

6. Wee A. Diagnostic utility of immunohistochemistry in hepatocellular carcinoma, its variants and their mimics. Appl Immunohistochem Mol Morphol 2006;14: 266-272.

7. Kakar S, Gown AM, Goodman ZD, Ferrell LD. Best practices in diagnostic immunohistochemistry: hepatocellular carcinoma versus metastatic neoplasms. Arch 
Pathol Lab Med 2007;131: 1648-1654.

8. Stroescu C, Herlea V, Dragnea A, Popescu I. The diagnostic value of cytokeratins and carcinoembryonic antigen immunostaining in differentiating hepatocellular carcinomas from intrahepatic cholangiocarcinomas. J Gastrointestin Liver Dis. 2006 ;15:9-14.

9. Saad RS, Luckasevic TM, Noga CM, Johnson DR, Silverman JF, Liu YL.Diagnostic value of HepPar1, pCEA, CD10, and CD34 expression in separating hepatocellular carcinoma from metastatic carcinoma in fine-needle aspiration cytology. Diagn Cytopathol 2004;30:1-6.

10. Wee A. Diagnostic utility of immunohistochemistry in hepatocellular carcinoma, its variants and their mimics. $A p p l$ Immunohistochem Mol Morphol 2006 ;14:266-72.

11. Filmus J, Selleck SB. Glypicans: proteoglycans with a surprise. J Clin Invest. 2001; 108:497-501.

12. Huang N, Lin J, Ruan J, Su N, Qing R, Liu F, et al. MiR-219-5p inhibits hepatocellular carcinoma cell proliferation by targeting glypican-3. FEBS Lett. 2012;586:884-91.

13. Farooq M, Hwang SY, Park MK, Kim JC, Kim MK, Sung YK. Blocking endogenous glypican3 expression releases Hep 3B cells from G1 arrest. Mol Cells. 2003;15:356-360.

14. Li L, Jin R, Zhang X, Lv F, Liu L, Liu D, et al. Oncogenic activation of GPC3 by c-Myc in human hepatocellular carcinoma. Hepatology 2012 18. doi: 10.1002/hep.25891.

15. Ning S, Bin C, Na H, Peng S, Yi D, Xiang-hua $\mathrm{Y}$, et al. Glypican-3, a novel prognostic marker of hepatocellular cancer, is related with postoperative metastasis and recurrence in hepatocellular cancer patients. Mol Biol Rep 2012;39(1):351-7.

16. Zhu ZW, Friess H, Wang L, Abou-Shady M, Zimmermann A, Lander AD, et al. Enhanced glypican-3 expression differentiates the majority of hepatocellular carcinomas from benign hepatic disorders. Gut 2001;48:558-564.

17. Yamauchi N, Watanabe A, Hishinuma M, Ohashi $\mathrm{K}$, Midorikawa Y, Morishita Y, et al. The glypican 3 oncofetal protein is a promising diagnostic marker for hepatocellular carcinoma. Mod Pathol. 2005;18:1591-1598.

18. Capurro M, Wanless IR, Sherman M, Deboer G, Shi W, Miyoshi E., et al. Glypican-3: a novel serum and histochemical marker for hepatocellular carcinoma. Gastroenterology 2003;125:89-97.
19. Nakatsura T, Yoshitake Y, Senju S, Monji M, Komori H, Motomura Y, et al. Glypican-3, overexpressed specifically in human hepatocellular carcinoma, is a novel tumor marker. Biochem Biophys Res Commun. 2003;306:1625.

20. Hirohashi S, Blum HE, Ishak KJ. Hepatocellular Carcinoma. In Who: Pathology \& Genetics, Tumour of the digestive system. IARC Press 2000;159-172.

21. Asia-Pacific Working Party on Prevention of Hepatocellular Carcinoma. Prevention of hepatocellular carcinoma in the Asia-Pacific region: consensus statements. J Gastroenterol Hepatol. 2010;25:657-63.

22. Committee of Liver Cancer, Chinese Anticancer Association. The clinical diagnosis and staging criteria of primary liver cancers. Journal of Chinese Hepatology. 2001; 9: 324-328.

23. Yang HI, Yuen MF, Chan HL, Han KH, Chen PJ, Kim DY, rt al.Risk estimation for hepatocellular carcinoma in chronic hepatitis B (REACH-B): development and validation of a predictive score. Lancet Oncol. 2011;12:568-74

24. Lu J, Zhou Y, Lin X, Jiang Y, Tian R, Zhang Y, et al. General epidemiological parameters of viral hepatitis $A, B, C$, and $E$ in six regions of China: a cross-sectional study in 2007. PLoS One 2009; 4:e8467.

25. Kandil D, Leiman G, Allegretta M, Trotman W, Pantanowitz L, Goulart R, et al. Glypican-3 Immunocytochemistry in Liver Fine-needle Aspirates-A Novel Stain to Assist in the Differentiation of Benign and Malignant Liver Lesions. Cancer (Cancer Cytopathology) 2007; 111: 316-322.

26. Zhang L, Liu H, Sun L, Li N, Ding H, Zheng J.Glypican-3 as a potential differential diagnosis marker for hepatocellular carcinoma: a tissue microarray-based study. Acta Histochem 2012;114:547-52.

27. Wang Y, Shen Z, Zhu Z, Han R, Huai M.Clinical values of AFP, GPC3 mRNA in peripheral blood for prediction of hepatocellular carcinoma recurrence following OLT: AFP, GPC3 mRNA for prediction of HCC. Hepat Mon 2011;11:1959.

28. Tremosini S, Forner A, Boix L, Vilana R, Bianchi $\mathrm{L}$, Reig M, et al.Prospective validation of an immunohistochemical panel (glypican 3, heat shock protein 70 and glutamine synthetase) in liver biopsies for diagnosis of very early 
hepatocellular carcinoma. Gut 2012doi:10.1136/ gutjnl-2011-301862

29. Tan CH, Low SC, Thng CH. APASL and AASLD Consensus Guidelines on Imaging Diagnosis of Hepatocellular Carcinoma: A Review. Int J Hepatol, 2011;2011:519783.

30. Baumhoer D., Tornillo L., Stadlmann S., Roncalli M., Diamantis EK., Terracciano LM. Glypican 3 expression in human nonneoplastic, preneoplastic, and neoplastic tissues: a tissue microarray analysis of 4,387 tissue samples. Am
J Clin Pathol. 2008;129:899-906.

31. Singal AG, Conjeevaram HS, Volk ML, Fu S, Fontana RJ, Askari F, et al.Effectiveness of hepatocellular carcinoma surveillance in patients with cirrhosis. Cancer Epidemiol Biomarkers Prev. 2012;21:793-9.

32. Ozkan H, Erdal H, Koçak E, Tutkak H, Karaeren Z, Yakut M, et al.Diagnostic and prognostic role of serum glypican 3 in patients with hepatocellular carcinoma. J Clin Lab Anal. 2011;25:350-3. 